\title{
Excision Can Be Delayed until Size Grows in Small Papillary Lesions of the Breast
}

\author{
Jae Young Jang, M.D., Isaac Kim, M.D., Ph.D., Seung Ah Lee, M.D., Seung Ki Kim, M.D. \\ Division of Breast Surgery, Department of Surgery, CHA Bundang Medical Center, CHA University, Seongnam, Korea
}

Purpose: The management of intraductal papilloma (IDP) without atypia remains controversial. This study evaluated the manifestations and incidence of malignancy during observation without surgery in patients diagnosed with IDP by core needle biopsy (CNB), to confirm whether close follow-up instead of surgical treatment is the preferred treatment option in selected patients. Methods: We retrospectively reviewed the data of 589 patients diagnosed with IDP by CNB between January 2009 to December 2018. The data of the 102 IDP lesions from 90 women who did not undergo immediate excision were analyzed. Of these, 84 patients received imaging follow-up without excision, while 18 patients underwent delayed excision during follow-up. Results: During the median follow-up period of 18.6 months, the mean change in tumor size and mean percent change in tumor size were $-0.06 \mathrm{~cm}$ and $-0.22 \%$, respectively. Delayed excision was performed in 18 patients (17.6\%). In the delayed excision group, three (16.7\%) patients and one (5.6\%) patient were diagnosed with atypical papilloma and intraductal papillary carcinoma, respectively, based on the final pathological findings. The upstaged group (atypia and malignancy; four patients) showed a $62.0 \%$ increase in the tumor size, which is higher than the benign group that showed a 10.4\% increase in tumor size. However, the difference was not statistically significant $(p=0.185)$. Conclusion: Observation without excision is possible for small IDP without atypia, because of the minimal changes in tumor size and low incidence of malignancy after excision. However, to avoid a missed diagnosis of malignancy, excision should be considered if the lesion increases in size during follow-up.

Key Words: Breast, Intraductal papilloma, Neoplasms

\section{INTRODUCTION}

Papillary lesions of the breast are commonly diagnosed by core needle biopsy (CNB) and the clinical presentations of these lesions vary, such as spontaneous nipple discharge and, infrequently, palpable nodules. Moreover, these lesions are detected by imaging without any symptoms. The pathological spectra of papillary lesions vary, including intraductal papilloma (IDP), papillomatosis, atypical papilloma, and intraductal papillary carcinoma [1]. Thus, differentiating between benign and malignant lesions by CNB is challenging. Moreover, according to the IDP location, the risk of cancerous changes may increase by up to $37.5 \%$ [2]. Hence, excision for pathological confirmation has been traditionally recommended. The possibility of malignant transformation after long-term follow-up is another reason for excision after CNB-confirmed IDP [3-5].

Correspondence: Seung Ah Lee, M.D.

Department of Surgery, CHA Bundang Medical Center, 59 Yatap-ro, Bundang-gu, Seongnam 13496, Korea

Tel: +82-31-780-5257, Fax: +82-31-780-5266, E-mail: mdseungah@chamc.co.kr Received: Oct 4, 2019 Revised: Nov 6, 2019 Accepted: Apr 19, 2020
Previous studies advocated immediate excision due to the significant upgrade rate to cancer from benign IDP after surgery or during follow-up [6-12]. In recent studies, close surveillance rather than surgery may be considered in the subgroup of patients, with small lesion size [13,14], non-palpability [15], radiological-pathological concordance $[14,15]$, or no personal history of breast cancer [16]. The rationale for close observation in patients with CNB-confirmed IDP is the low upgrade rate to malignancy at the time of surgery [13-19].

The present study evaluated the changes in the clinical course of IDP and rates of malignancy development during close observation without excision to confirm whether close follow-up instead of unnecessary surgical treatment is the preferred treatment in selected patients, diagnosed with IDP by CNB.

\section{METHODS}

We searched the pathology database for patients diagnosed with IDP at CHA Bundang medical center between January 2009 and December 2018. The diagnosis was established by CNB. Each pathologi- 
cal report of IDP was considered an individual "case”.

The search yielded $589 \mathrm{CNB}$ results. We excluded 11 patients with atypia, 286 patients who underwent immediate excision within 6 months after $\mathrm{CNB}$, and 190 patients with a follow-up period of less than 6 months or who lost to follow-up. Finally, we obtained 102 reports of IDP without atypia from 90 women (Figure 1).

Ultrasonographic (US) examinations and US-guided CNB were performed by designated radiologists. US images were obtained using an Aixplorer (SuperSonic Imagine SA., Aix-en-Provence, France), and $\mathrm{CNB}$ was performed using a 14-gauge needle.

We divided the patients into two groups: patients who were followed-up without excision $(\mathrm{n}=84)$, and patients with delayed excision during follow-up $(n=18)$. There is no official institutional policy on when to consider excision. Generally, the decision was made by individual physicians, when the following were observed; when the follow-up image had new suspicious findings (Increased vascularity, change of marginal irregularity), when the lesion showed an increase of $20 \%$ or higher in longest dimension within 6 months, and when the patient wanted to excise the lesion instead of undergoing follow-up.

The medical records of all patients were reviewed for clinical information including the patient's age, follow-up duration, personal and family history of breast cancer, biopsy-confirmed IDP history other than the current lesion, and clinical presentation. Tumor characteris- tics such as size, location, and multiplicity were also reviewed. We defined lesions located within and more than $2 \mathrm{~cm}$ from the nipple as central and peripheral locations, respectively. Multiplicity was defined as the presence of more than one papillary lesion found by concurrent US in the ipsilateral breast. Both groups were further analyzed by assessing the changes in tumor size, changes in imaging findings, and reasons for excision. In every patient, the initial tumor size was that determined by US imaging just before $\mathrm{CNB}$, and the last tumor size was measured at the most recent US during the follow-up period. The percent change in tumor size was defined as the change in tumor size during the follow-up period as a percentage of the initial tumor size. This represents the relative size increase during follow-up in comparison with the initial size in terms of proportion.

Statistical analysis was performed using the International Business Machines (IBM) Corporation Statistical Package for the Social Sciences Statistics for Windows, version 25.0 (IBM Corp., Armonk, USA). Patients' demographics and clinical characteristics were compared using the chi-squared test for categorical variables (location, multiplicity, Breast Imaging Reporting and Data System [BIRADS] category, cores, symptoms, and personal or familial history). The Fisher's exact test was used when the number of patients in each group was insufficient to perform the chi-squared test. The Student's t-test was used to evaluate the association between the continuous variables

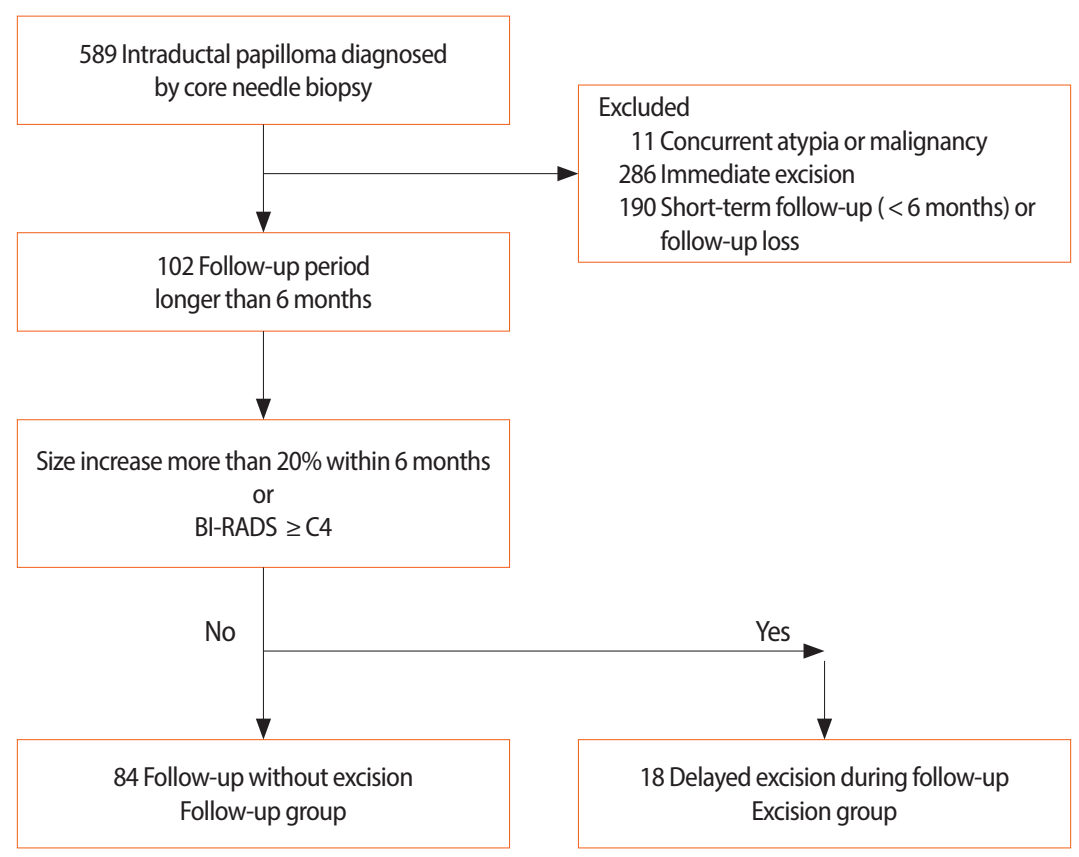

Figure 1. Flowchart of the subject group exclusion and assignment. 
(age, follow-up duration, and tumor size). All tests were two-sided and $p$ values $<0.05$ were considered statistically significant.

This study was approved by the Institutional Review Board and ethics committees of CHA Bundang medical center (IRB No. CHAMC 2019-10-016-005).

\section{RESULTS}

\section{Clinical manifestations of patients}

The demographics and clinical manifestations of 102 IDP lesions from 90 patients are presented in Table 1. The mean age of the patients was 46.4 (range; $23-80$ ) years. The median follow-up durations were

Table 1. Clinical manifestations of 102 core needle biopsy diagnosed benign intraductal papilloma lesions

\begin{tabular}{|c|c|c|c|c|c|}
\hline \multirow{3}{*}{ Variable } & & Total & $\begin{array}{l}\text { Follow up } \\
\text { group }\end{array}$ & $\begin{array}{c}\text { Delayed excision } \\
\text { group }\end{array}$ & \multirow{3}{*}{$p$-value } \\
\hline & Case & 102 & 84 & 18 & \\
\hline & Patient & 90 & 73 & 17 & \\
\hline Age (yr), mean (range) & & $46.4(23-80)$ & $46.5(23-80)$ & $45.8(37-70)$ & 0.784 \\
\hline Follow up duration (mo), median (range) & & $18.6(6.1-120.9)$ & $20.0(6.1-120.9)$ & $15.5(6.7-104.4)$ & 0.276 \\
\hline Initial tumor size (cm) & & $0.79 \pm 0.36$ & $0.75 \pm 0.31$ & $0.94 \pm 0.50$ & 0.019 \\
\hline Last tumor size $(\mathrm{cm})$ & & $0.73 \pm 0.50$ & $0.66 \pm 0.42$ & $1.04 \pm 0.69$ & 0.003 \\
\hline Percent change in tumor size (\%) & & $+0.22 \pm 61.6$ & $-4.40 \pm 59.6$ & $+21.8 \pm 67.4$ & 0.101 \\
\hline Previous IDP history* (patient; No. \%) & & & & & 0.413 \\
\hline No & & $63(70.0)$ & $53(72.6)$ & $10(58.8)$ & \\
\hline Yes & & $27(30.0)$ & $20(27.4)$ & $7(41.2)$ & \\
\hline Tumor location ${ }^{\dagger}$ (case; No. \%) & & & & & 0.494 \\
\hline Central & & $85(83.3)$ & $71(84.5)$ & $14(77.8)$ & \\
\hline Peripheral & & $17(16.7)$ & $13(15.5)$ & $4(22.2)$ & \\
\hline BIRADS at initial US (case; No. \%) & & & & & 0.186 \\
\hline C3 & & $20(19.6)$ & $14(16.7)$ & $6(33.3)$ & \\
\hline C4a & & 79 (77.5) & $68(81.0)$ & $11(61.1)$ & \\
\hline C4b & & $3(2.9)$ & $2(2.4)$ & $1(5.6)$ & \\
\hline Multiplicity ${ }^{\ddagger}$ (patient; No. \%) & & & & & 1.000 \\
\hline Solitary & & $73(81.1)$ & $60(82.2)$ & $13(76.5)$ & \\
\hline Multiple & & $17(18.9)$ & $13(14.4)$ & $4(23.5)$ & \\
\hline Number of CNB cores (case; No. \%) & & & & & 0.305 \\
\hline$\leq 3$ & & $5(4.9)$ & $5(6.0)$ & 0 & \\
\hline 4 & & $80(78.4)$ & $66(78.6)$ & $14(77.8)$ & \\
\hline 5 & & $15(14.7)$ & $12(14.3)$ & $3(16.7)$ & \\
\hline$\geq 6$ & & $2(2.0)$ & $1(1.2)$ & $1(5.6)$ & \\
\hline Symptom (case; No. \%) & & & & & 0.034 \\
\hline No symptom & & $84(82.4)$ & $69(82.1)$ & $15(83.3)$ & \\
\hline Palpable mass & & $4(3.9)$ & $3(3.6)$ & $1(5.6)$ & \\
\hline Serous nipple discharge & & $7(6.9)$ & $7(8.3)$ & 0 & \\
\hline Bloody nipple discharge & & $3(2.9)$ & $3(3.6)$ & 0 & \\
\hline Breast pain & & $2(2.0)$ & 0 & $2(11.1)$ & \\
\hline Palpable mass \& serous nipple discharge & & $2(2.0)$ & $2(2.4)$ & 0 & \\
\hline Personal history of breast cancer ${ }^{\S}$ (patient; No. \%) & & & & & 0.583 \\
\hline No & & $86(95.6)$ & $69(94.5)$ & $17(100)$ & \\
\hline Yes & & $4(4.44)$ & $4(5.5)$ & 0 & \\
\hline Family history of breast cancer" (patient; No. \%) & & & & & 0.587 \\
\hline No & & $84(93.3)$ & $67(91.8)$ & $17(100)$ & \\
\hline Yes & & $6(6.67)$ & $6(8.2)$ & 0 & \\
\hline
\end{tabular}

$\mathrm{CNB}=$ core needle biopsy; IDP = intraductal papilloma; BI-RADS = breast imaging reporting and data system.

*IDP diagnosis by CNB, surgical excision or vacuum-assisted excision in ipsilateral breast, prior or concurrent; ${ }^{\dagger}$ Central lesions are defined as $\leq 2 \mathrm{~cm}$ from the nipple, and peripheral lesions are defined as $>2 \mathrm{~cm}$ from the nipple; ${ }^{\ddagger}$ More than one papillary lesions in ipsilateral breast are labeled as multiple lesions; ${ }^{5}$ Personal history including atypia, non-invasive and invasive cancer, prior or concurrent; "Family history including 1st-degree relative(parents and siblings). 
20.0 (range; 6.1-120.9) months in the follow-up group and 15.5 (range; 6.7-104.4) months in the delayed excision group. The mean initial tumor size was 0.79 (range; $0.3-2.0$ ) cm overall, and $81.1 \%$ of the patients had solitary lesions, $83.3 \%$ of the lesions were located in the central area, and most $(82.4 \%)$ patients had no specific symptom before the IDP diagnosis.

Among the lesions, 77.5\% were classified as BIRADS category C4a, $2.9 \%$ were $\mathrm{C} 4 \mathrm{~b}$, and $78.4 \%$ were diagnosed with 4 four $\mathrm{CNB}$ cores. Approximately $30.0 \%$ of patients had history of previous IDP, $4.4 \%$ had personal history of contralateral breast cancer and $6.7 \%$ had familial history of breast cancer. During the follow-up period, there were minimal changes in tumor size $(-0.06 \mathrm{~cm}$, [range; -1.3 to +1.2$])$, and the mean percent change of the tumor was $0.22 \%$.

The mean initial tumor size was significantly larger $(0.9 \mathrm{~cm}$, [range; 0.3-2.0]) in the delayed excision group than in the follow-up group $(0.75 \mathrm{~cm}$, [range; $0.3-1.8])(p=0.019)$. The mean tumor sizes decreased from $0.75 \mathrm{~cm}$ to $0.66 \mathrm{~cm}$ in the follow-up group, and increased from $0.94 \mathrm{~cm}$ to $1.04 \mathrm{~cm}$ in the delayed excision group. However, the change was not statistically significant $(p=0.160)$. Regarding percent change in tumor size, the delayed excision group had a relatively greater mean change of $+21.8 \%$ than did the follow-up group $(-4.4 \%)$. However, the difference was not statistically significant $(p=0.101)$. There were no differences in tumor location, multiplicity, clinical symptoms, and personal or familial cancer history between groups.

\section{Patterns in the changes in tumor size}

The pattern of tumor size change in both groups is shown in Table 2. IDP history or multiplicity did not affect tumor size change during follow-up. Meanwhile, in the follow-up group, 17 central lesions (23.9\%) and 8 peripheral lesions (61.5\%) had size increases with a statistically significant difference $(p=0.01)$. The difference in the percent change in tumor size (-7.92\% vs. $+14.7 \%)$ was not statistically significant between the two groups. While peripheral lesions more likely increased in size, the increase was not significant. This pattern was not observed in the delayed excision group.

\section{Comparisons between benign and upstaging in final pathology findings after excision}

During the follow-up period, 18 cases underwent delayed excision because of increase in tumor size (6 cases), because of the presence of suspicious lesions in sonographic findings ( 9 cases) and because of patient's preference (3 cases) (Table 3 ). After surgery, 14 cases $(77.8 \%)$ were diagnosed with benign papilloma in final pathological findings, 3 cases $(16.7 \%)$ were diagnosed with atypical papilloma and 1 cases (5.6\%) was diagnosed with intraductal papillary carcinoma. Comparison of benign and upstaged (atypia or malignancy) cases in the de-

Table 2. Tumor size change pattern comparison based on various tumor characteristics

\begin{tabular}{|c|c|c|c|c|c|c|c|c|c|c|}
\hline \multirow{3}{*}{$\begin{array}{l}\text { Variable } \\
\text { Follow up group }\end{array}$} & & \multicolumn{3}{|c|}{ Previous IDP history* } & \multicolumn{3}{|c|}{ Tumor location $^{\dagger}$} & \multicolumn{3}{|c|}{ Multiplicity ${ }^{\ddagger}$} \\
\hline & & No & Yes & \multirow{2}{*}{$p$-value } & \multirow{2}{*}{$\begin{array}{l}\text { Central } \\
n=71\end{array}$} & \multirow{2}{*}{$\begin{array}{c}\text { Peripheral } \\
n=13\end{array}$} & \multirow{2}{*}{$p$-value } & \multirow{2}{*}{$\begin{array}{l}\text { Solitary } \\
n=63\end{array}$} & \multirow{2}{*}{$\begin{array}{l}\text { Multiple } \\
n=21\end{array}$} & \multirow{2}{*}{$p$-value } \\
\hline & $\mathrm{n}=84$ & $n=57$ & $n=27$ & & & & & & & \\
\hline Initial tumor size (cm) & $0.75 \pm 0.31$ & $0.78 \pm 0.33$ & $0.67 \pm 0.25$ & 0.120 & $0.77 \pm 0.31$ & $0.62 \pm 0.25$ & 0.117 & $0.76 \pm 0.32$ & $0.71 \pm 0.26$ & 0.530 \\
\hline Last tumor size (cm) & $0.66 \pm 0.42$ & $0.71 \pm 0.46$ & $0.57 \pm 0.32$ & 0.171 & $0.66 \pm 0.42$ & $0.67 \pm 0.43$ & 0.946 & $0.66 \pm 0.44$ & $0.67 \pm 0.37$ & 0.906 \\
\hline$\%$ change in tumor size (\%) & $-4.40 \pm 59.6$ & $-4.12 \pm 61.0$ & $-5.02 \pm 57.9$ & 0.949 & $-7.92 \pm 58.8$ & $+14.7 \pm 63.1$ & 0.210 & $-7.36 \pm 58.1$ & $-4.43 \pm 64.8$ & 0.436 \\
\hline \multicolumn{2}{|l|}{ Trend of tumor change (No. \%) } & & & 0.985 & & & 0.017 & & & 0.491 \\
\hline Decreased or no change & $59(70.2)$ & $40(70.2)$ & $19(70.4)$ & & $54(76.1)$ & $5(38.5)$ & & $43(68.3)$ & $16(76.2)$ & \\
\hline Increased & $25(29.8)$ & $17(29.8)$ & $8(29.6)$ & & $17(23.9)$ & $8(61.5)$ & & $20(31.7)$ & $5(23.8)$ & \\
\hline Delayed excision group & $n=18$ & $n=10$ & $n=8$ & & $n=14$ & $n=4$ & & $n=14$ & $\mathrm{n}=4$ & \\
\hline Initial tumor size (cm) & $0.94 \pm 0.50$ & $0.89 \pm 0.55$ & $1.0 \pm 0.47$ & 0.505 & $0.99 \pm 0.55$ & $0.78 \pm 0.28$ & 0.783 & $0.93 \pm 0.51$ & $0.98 \pm 0.55$ & 0.580 \\
\hline Last tumor size (cm) & $1.04 \pm 0.69$ & $1.10 \pm 0.61$ & $0.98 \pm 0.82$ & 0.714 & $1.05 \pm 0.75$ & $1.03 \pm 0.49$ & 0.951 & $1.09 \pm 0.73$ & $0.90 \pm 0.58$ & 0.649 \\
\hline$\%$ change in tumor size $(\%)$ & $+21.8 \pm 67.4$ & $+45.5 \pm 75.2$ & $-7.67 \pm 44.5$ & 0.097 & $+19.5 \pm 64.3$ & $+30.1 \pm 87.8$ & 0.791 & $+25.0 \pm 58.5$ & $-11.0 \pm 103.4$ & 0.727 \\
\hline \multicolumn{2}{|l|}{ Trend of tumor change (No. \%) } & & & 0.367 & & & 1.000 & & & 1.000 \\
\hline Decreased or no change & $10(55.6)$ & $5(50.0)$ & $5(62.5)$ & & $8(57.1)$ & $2(50.0)$ & & $8(57.1)$ & $2(50.0)$ & \\
\hline Increased & $8(44.4)$ & $5(50.0)$ & $3(37.5)$ & & $6(42.9)$ & $2(50.0)$ & & $6(42.9)$ & $2(50.0)$ & \\
\hline
\end{tabular}

IDP = intraductal papilloma.

*IDP diagnosis by CNB, surgical excision or vacuum-assisted excision in ipsilateral breast, prior or concurrent; ${ }^{\dagger}$ Central lesions are defined as $\leq 2 \mathrm{~cm}$ from the nipple, and peripheral lesions are defined as $>2 \mathrm{~cm}$ from the nipple; ${ }^{\ddagger}$ More than one papillary lesions in ipsilateral breast are labeled as multiple lesion. 
Table 3. Clinical manifestations of 18 intraductal papillomas of patients underwent an excision during follow-up

\begin{tabular}{|c|c|c|c|c|}
\hline \multirow{4}{*}{ Variable } & & \multicolumn{3}{|c|}{ Final pathology after excision } \\
\hline & & Benign & Upstaged & \\
\hline & Case & 14 & 4 & $p$-value \\
\hline & Patient & 13 & 4 & \\
\hline Age (yr), mean (range) & & $43.9 \pm 6.26$ & $52.8 \pm 15.2$ & 0.089 \\
\hline Follow up duration (mo), median (range) & & $15.5(10.3-41.4)$ & $19.0(6.7-104.4)$ & 0.158 \\
\hline Initial tumor size (cm) & & $0.93 \pm 0.51$ & $0.98 \pm 0.55$ & 0.580 \\
\hline Last tumor size (cm) & & $0.94 \pm 0.75$ & $1.40 \pm 0.18$ & 0.254 \\
\hline Percent change in tumor size (\%) & & $+10.4 \pm 61.2$ & $+62.0 \pm 82.3$ & 0.185 \\
\hline Reason of excision (case; No. \%) & & & & 0.213 \\
\hline Size increase & & $3(21.4)$ & $3(75.0)$ & \\
\hline Still suspicious sonographic finding & & $8(57.1)$ & $1(25.0)$ & \\
\hline Patient's preference & & $3(21.4)$ & 0 & \\
\hline Previous IDP history* (patient; No. \%) & & & & 0.588 \\
\hline No & & $7(53.8)$ & $3(75.0)$ & \\
\hline Yes & & $6(46.2)$ & $1(25.0)$ & \\
\hline Tumor location $^{\dagger}$ (case; No. \%) & & & & 0.197 \\
\hline Central & & $12(85.7)$ & $2(50.0)$ & \\
\hline Peripheral & & $2(14.3)$ & $2(50.0)$ & \\
\hline BIRADS at last US (case; No. \%) & & & & 0.664 \\
\hline $\mathrm{C} 3$ & & $3(21.4)$ & 0 & \\
\hline C4a & & $11(78.6)$ & $4(100)$ & \\
\hline Multiplicity ${ }^{\ddagger}$ (patient; No. \%) & & & & 0.197 \\
\hline Solitary & & $11(84.6)$ & $2(50.0)$ & \\
\hline Multiple & & $2(15.4)$ & $2(50.0)$ & \\
\hline Symptom (case; No. \%) & & & & 0.598 \\
\hline No symptom & & $11(78.6)$ & $4(100)$ & \\
\hline Palpable mass & & $1(7.1)$ & 0 & \\
\hline Nipple discharge & & 0 & 0 & \\
\hline Ipsilateral breast pain & & $2(14.3)$ & 0 & \\
\hline Personal history of breast cancer ${ }^{\S}$ (patient; No. \%) & & & & NA \\
\hline No & & $13(100)$ & $4(100)$ & \\
\hline Yes & & 0 & 0 & \\
\hline Family history of breast cancer" (patient; No. \%) & & & & NA \\
\hline No & & $13(100)$ & $4(100)$ & \\
\hline Yes & & 0 & 0 & \\
\hline
\end{tabular}

IDP = intraductal papilloma; BIRADS = breast imaging reporting and data system; $C N B=$ core needle biopsy; $N A=$ not available.

*IDP diagnosis by CNB, surgical excision or vacuum-assisted excision in ipsilateral breast, prior or concurrent; ${ }^{\dagger}$ Central lesions are defined as $\leq 2 \mathrm{~cm}$ from the nipple, and peripheral lesions are defined as $>2 \mathrm{~cm}$ from the nipple; ${ }^{\ddagger}$ More than one papillary lesions in ipsilateral breast are labeled as multiple lesions; ${ }^{5}$ Personal history including atypia, non-invasive and invasive cancer, prior or concurrent; "Family history including 1st-degree relative(parents and siblings).

layed excision group showed that the most common reason for excision in the upstaged group was an increase in tumor size (75.0\%). In contrast, suspicious sonographic finding was the most frequent (57.1\%) reason in the benign group. The mean age of the patients in the benign group (43.9 years) was lower than that in the upstaged group (52.8 years), with borderline statistical significance $(p=0.089)$, while the mean tumor size at the last follow-up was higher in the upstaged group $(1.4 \mathrm{~cm})$ than that in the benign group $(0.94 \mathrm{~cm})$, although the difference was not statistically significant $(p=0.254)$. The mean changes in tumor size and mean percent change in tumor size were larger in the upstaged group $(+0.43 \mathrm{~cm}$ and $+62.0 \%$, respectively) than those in the benign group $(+0.01 \mathrm{~cm}$ and $+10.4 \%$, respectively), although the differences were not statistically significant $(p=0.369$ and $p=0.185$, respectively). There were no differences in IDP history or individual or familial history of breast cancer between groups. Moreover, differences were not observed between groups in tumor location, multiplicity, sonographic BIRADS category just before excision and clinical symptoms. 
Table 4. Summary of 4 patients whose benign lesion upstaged to atypia or malignancy in final pathology

\begin{tabular}{|c|c|c|c|c|c|c|c|c|c|}
\hline Sex/Age & $\begin{array}{c}\text { Final } \\
\text { pathology }\end{array}$ & $\begin{array}{l}\text { Reason of } \\
\text { excision }\end{array}$ & $\begin{array}{c}\text { Previous } \\
\text { IDP } \\
\text { history }\end{array}$ & $\begin{array}{l}\text { Follow up } \\
\text { duration } \\
\text { (months) }\end{array}$ & $\begin{array}{l}\text { Change in } \\
\text { tumor size } \\
(\mathrm{cm})\end{array}$ & $\begin{array}{l}\text { Percent } \\
\text { change in } \\
\text { tumor size } \\
(\%)\end{array}$ & Location & BIRADS & $\begin{array}{l}\text { Sonographic description } \\
\text { before excision }\end{array}$ \\
\hline $\begin{array}{l}\text { Patient } 1 \\
\mathrm{~F} / 70\end{array}$ & Atypical papilloma & $\begin{array}{l}\text { Suspicious sono- } \\
\text { graphic finding }\end{array}$ & No & 14.3 & $1.7 \rightarrow 1.6(-0.1)$ & -5.9 & Central & $\mathrm{C} 4 \mathrm{a} \rightarrow \mathrm{C} 4 \mathrm{a}$ & $\begin{array}{l}\text { Irregular, microlobulated } \\
\text { nodule }\end{array}$ \\
\hline $\begin{array}{l}\text { Patient } 2 \\
\mathrm{~F} / 40\end{array}$ & Atypical papilloma & Size increase & Yes & 23.8 & $1.1 \rightarrow 1.5(+0.4)$ & +36.4 & Peripheral & $\mathrm{C} 4 \mathrm{a} \rightarrow \mathrm{C} 4 \mathrm{a}$ & $\begin{array}{l}\text { Increased AP diameter and } \\
\text { complex cystic change }\end{array}$ \\
\hline $\begin{array}{l}\text { Patient } 3 \\
\text { F/40 }\end{array}$ & Atypical papilloma & Size increase & No & 104.4 & $0.5 \rightarrow 1.3(+0.8)$ & +160.0 & Peripheral & $\mathrm{C} 3 \rightarrow \mathrm{C} 4 \mathrm{a}$ & $\begin{array}{l}\text { Ductal extension and cystic } \\
\text { change in peripheral portion }\end{array}$ \\
\hline $\begin{array}{l}\text { Patient } 4 \\
\text { F/61 }\end{array}$ & $\begin{array}{l}\text { Intraductal papil- } \\
\text { lary carcinoma }\end{array}$ & Size increase & Yes & 6.7 & $0.6 \rightarrow 1.2(+0.6)$ & +100.0 & Central & $\mathrm{C} 3 \rightarrow \mathrm{C} 4 \mathrm{a}$ & $\begin{array}{l}\text { Cystic mass with newly } \\
\text { appeared wall thickening }\end{array}$ \\
\hline
\end{tabular}

IDP = intraductal papilloma; BIRADS = breast imaging reporting and data system.

\section{Upstaged cases}

Table 4 shows the details of the 4 patients diagnosed with atypia or carcinoma in situ after excision. Among the 3 patients with atypical papilloma, 2 patients showed $36.4 \%$ and $160 \%$ change in tumor size, during the follow-up period of 23.8 months and 104.4 months, respectively. One had a slightly reduced percentage change of 5.9. Two patients with tumor size increase had peripheral tumors, and both had cystic changes in the lesions by US. The patient with cancer in final pathology was older (61 years), and had a centrally-located tumor with a change from BIRADS category $\mathrm{C} 3$ in the initial US to C4a in the last US. The tumor size increased by $0.6 \mathrm{~cm}$ (from $0.6 \mathrm{~cm}$ to 1.2 $\mathrm{cm}$ ) during the 6 month follow-up period. US findings revealed wall thickening of a known cystic mass, which was not prominent in previous examinations.

\section{DISCUSSION}

Once the diagnosis is confirmed, the management of IDP depends on the histologic features of the lesion. In the literature, IDP with atypia is considered a high-risk lesion, for which surgical excision is recommended $[3,19]$. Long-term follow-up of benign breast disease with atypia from 1967 to 1991 showed increased cancer risk, with a relative risk of 4.24 [3]. A recent study also analyzed long-term cancer development in papilloma with atypia [19]. For patients who underwent excision following CNB diagnosis, the 10-year cancer-free survival rate was $93.8 \%$ for patients with IDP without atypia. However, the cancer-free survival rates were, $84.7 \%$ for IDP with atypia and $77.4 \%$ for IDP with atypical ductal hyperplasia or atypical lobular hyperplasia.
In a meta-analysis conducted in 2013, the pooled estimate for the percentage of underestimation was $15.7 \%$ [5]. The factors associated with higher underestimation were atypical lesions, positive mammographic findings, and articles published before 2005. An international multicenter study also reported that the risk of malignancy was significantly associated with the presence of atypia, with an upgrade rate of $14.4 \%$ in final pathology findings after surgery [20]. Other previous studies have confirmed that excision is considered the appropriate management for papilloma $[11,21,22]$.

Furthermore, the management of IDP without atypia remains controversial. Several studies have suggested the surgical excision of the lesion, while others have recommended close surveillance instead. Jacobs et al. [23] published a review article recommending excision for all papillary lesions even those with completely benign features due to the small but definite chance of atypia or malignancy on excision following CNB. Rizzo et al. [24] investigated 234 IDP lesions without atypia in which surgical pathology revealed 42 (17.9\%) lesions upgraded into atypia and 21 (9\%) lesions upgraded into malignancy. Another study evaluated 59 CNB-confirmed benign IDP lesions [6] and reported that 17 (29\%) and 6 (10\%) lesions upgraded into atypia and malignancy, respectively. Similar studies have shown an upgrade rate of $26.1 \%$ or $21.7 \%$ [25,26], confirming that surgical excision in lesions without atypia is the appropriate treatment strategy for these lesions.

Besides the upgrade rates, Moon et al. [7] followed up 265 papilloma patients after excision and determined the relative risks of long-term malignancy using ultrasonography in 8,971 patients without benign lesions as a reference. The relative risks were 5.2 in the first 2-year of follow-up period, and 2.2 during the next 2-year follow-up period, suggesting the need for excision in papilloma cases. 
However, according to recent studies, whether excision might be unnecessary in a subset of patients with benign IDPs remains unclear. Swapp et al. [17] reported an upgrade rate of $0 \%$ in 77 women with benign solitary IDP. Studies conducted in 2010-2016 reported low upgrade rates from $2.3 \%$ to $6.7 \%$, confirming that close imaging follow-up rather than surgical excision is the preferred treatment strategy $[13,15,16,18]$.

The most common factors associated with malignancy are tumor size and age. Youk et al. [27] reported a significantly increased upgrade rate in patients aged 50 years and with lesion sizes measuring $1 \mathrm{~cm}$ or greater. Moreover, a prospective observational study published in 2016 reported age and size as predictive factors [28]. Of the $234 \mathrm{pa}-$ tients diagnosed with IDP without atypia, upgrade-related factors were age ( $>54$ years) and mass size $(>1 \mathrm{~cm})$. Recent studies also proposed lesion size from $>1 \mathrm{~cm}$ to $>1.5 \mathrm{~cm}$ as a potential predictive factor $[13,14,29]$. Other factors such as prior breast atypia or cancer history, palpability, peripheral location and radiological-pathological discordance have also been evaluated, but discrepancy among study results has been observed.

Other than the upgrade rates and factors associated with excised IDPs confirmed by $\mathrm{CNB}$, further studies are required to determine the factors indicative of excision in which close follow-up should be ruled out. The present study searched for an evidence-based management strategy to decide when surgery should be performed during observation. Among various factors, we propose that a large increase in tumor size during follow-up rather than the initial tumor size indicates the need for surgical treatment.

Of the 102 IDP patients in our study, 18 underwent delayed excision during the follow-up period due to an increase in tumor size greater than $20 \%$ or the presence of suspicious findings on US. The upstaging rates to atypia and malignancy were $16.7 \%$ and $5.6 \%$, respectively, in the delayed excision group. The overall upgrade rate was $22.2 \%$, which is higher rate than those reported in recent studies (2.3\% to $6.7 \%)$ $[13,15,16,18]$. These differences may be due to a bias in patient selection while performing surgical excision. In recent studies, surgical excision was performed immediately in all patients diagnosed with IDP by CNB. However, in our study, we initially performed observation with follow-up of imaging study and subsequently determined the excision in case of significant change (greater than 20\%) in tumor size or suspicious changes in sonographic finding, depending on the reporting system of BIRADS. There may be relatively higher possibility of upstaging in selected patients.

Regardless of the reason for excision, the change in tumor size tended to be greater during a relatively shorter period in the delayed excision group than in the follow-up group. The percent change in tumor size in the delayed excision group was larger $(+21.8 \%)$ during a median follow-up of 15.5 months than that of the follow-up group (-4.4\%) in a median follow-up of 20.0 months. A similar pattern in percent change of tumor size was observed in the delayed excision group between benign and upstaged lesions. The upstaged group showed a higher percent change in tumor size (+62.0\%) than the benign group $(+10.4 \%)$, but the differences were not statistically significant $(p=0.185)$. We presume that statistical significance could be achieved if a larger number of patients were enrolled. The delayed excision group has a relatively small number of cases than the follow-up group.

The final pathological diagnosis of the only malignancy case was noninvasive cancer. The case had a $100 \%$ percent increase in tumor size during the 6-months of follow-up period, which was shorter than the median follow-up of 19.0 months in the upstaged cases in the delayed excision group. Regarding sonographic findings in this case, a cystic mass with newly observed wall thickening was noted. The BIRADS category was upgraded from C3 to C4a. The other two lesions that were upgraded to atypia also had cystic changes in the last US examination. Although this study did not define cystic change or notable sonographic changes requiring careful attention, excision should be considered instead of follow-up continuation to rule out malignancy when tumor size increases significantly or newly developed suspicious findings are observed within a short follow-up period.

Since this study was evaluated retrospectively, the delayed excision group had different surgical indication, including patient's preference. Additionally, considering the small number of patients from a single institution, significant statistical results, which may provide reliable evidence in a larger number of patients with consistent surgical indication and long-term surveillance, were not presented in this study. Hence, further studies are required to assess the association between the possibility of malignancy and change in tumor size or specific changes that may be suspected of malignancy in sonographic findings.

In conclusion, close observation with follow-up imaging instead of immediate excision is considered appropriate in patients diagnosed 
with IDP without atypia by $\mathrm{CNB}$ and in patients with relatively small initial tumor size and concordant radiological-pathological findings. However, if tumor size increases short term, specifically in elderly patients with changes in radiological findings, then excision should be considered to avoid missing underestimated atypia or malignancy.

\section{CONFLICT OF INTEREST}

The authors declare that they have no competing interests.

\section{REFERENCES}

1. Ueng SH, Mezzetti T, Tavassoli FA. Papillary neoplasms of the breast: a review. Arch Pathol Lab Med 2009;133:893-907.

2. Ohuchi N, Abe R, Kasai M. Possible cancerous change of intraductal papillomas of the breast; a 3-D reconstruction study of 25 cases. Cancer 1984;54:605-11.

3. Hartmann LC, Sellers TA, Frost MH, Lingle WL, Degnim AC, Ghosh K, et al. Benign breast disease and the risk of breast cancer. N Engl J Med 2005;353:229-37.

4. Kim JW, Kim YS, Kim KC. Feasibility and safety of ultrasound-guided vacuum-assisted breast biopsy system for intraductal papilloma. J Breast Dis 2015;3:56-9.

5. Wen X, Cheng W. Nonmalignant breast papillary lesions at core-needle biopsy: a meta-analysis of underestimation and influencing factors. Ann Surg Oncol 2013;20:94-101.

6. Shouhed D, Amersi FF, Spurrier R, Dang C, Astvatsaturyan K, Bose $\mathrm{S}$, et al. Intraductal papillary lesions of the breast, clinical and pathological correlation. Am Surg 2012;18:1161-5.

7. Moon HJ, Jung I, Kim MJ, Kim EK. Breast papilloma without atypia and risk of breast carcinoma. Breast J 2014;20:525-33.

8. Shiino S, Tsuda H, Yoshida M, Jimbo K, Asaga S, Hojo T, et al. Intraductal papillomas on core biopsy can be upgraded to malignancy on subsequent excisional biopsy regardless of the presence of atypical features. Pathol Int 2015;65:293-300.

9. Tatarian T, Sokas C, Rufail M, Lazar M, Malhotra S, Palazzo JP, et al. Intraductal papilloma with benign pathology on breast core biopsy: to excise or not? Ann Surg Oncol 2016;23:2501-7.

10. Tran HT, Mursleen A, Mirpour S, Ghanam O, Farha MJ. Papillary breast lesions association with malignancy and upgrade rates on surgical excision. Am Surg 2017;83:1294-7.

11. Zaleski M, Chen YA, Chetlen AL, Mack J, Xu L, Dodge DG, et al. Should we excise? Are there any clinical or histologic features that predict upgrade in papillomas, incidental or non-incidental? Ann Diagn Pathol 2018;35:62-8.

12. Chen YA, Mack JA, Karamchandani DM, Zaleski MP, Xu L, Dodge DG, et al. Excision recommended in high-risk patients: Revisiting the diagnosis of papilloma on core biopsy in the context of patient risk. Breast J 2019;25:232-6

13. Ko D, Kang E, Park SY, Kim SM, Jang M, Yun B, et al. The management strategy of benign solitary intraductal papilloma on breast core biopsy. Clin Breast Cancer 2017;17:367-72.

14. Symbol B, Ricci A Jr. Management of intraductal papilloma without atypia of the breast diagnosed on core biopsy: size and sampling matter. Breast J 2018;24:738-42

15. Nakhlis F, Ahmadiyeh N, Lester S, Raza S, Lotfi P, Golshan M. Papilloma on core biopsy: excision vs. observation. Ann Surg Oncol 2015;22:1479-82.

16. Kiran S, Jeong YJ, Nelson ME, Ring A, Johnson MB, Sheth PA, et al. Are we overtreating intraductal papillomas? J Surg Res 2018;231: $387-94$.

17. Swapp RE, Glazebrook KN, Jones KN, Brandts HM, Reynolds C, Visscher DW, et al. Management of benign intraductal solitary papilloma diagnosed on core needle biopsy. Ann Surg Oncol 2013;20: 1900-5.

18. Pareja F, Corben AD, Brennan SB, Murray MP, Bowser ZL, Jakate K, et al. Breast intraductal papillomas without atypia in radiologic-pathologic concordant core-needle biopsies: rate of upgrade to carcinoma at excision. Cancer 2016;122:2819-27.

19. Khan S, Diaz A, Archer KJ, Lehman RR, Mullins T, Cardenosa G, et al. Papillary lesions of the breast: to excise or observe? Breast J 2018; 24:350-5.

20. Foley NM, Racz JM, Al-Hilli Z, Livingstone V, Cil T, Holloway CM, et al. An international multicenter review of the malignancy rate of excised papillomatous breast lesions. Ann Surg Oncol 2015;22: S385-90.

21. Renshaw AA, Derhagopian RP, Tizol-Blanco DM, Gould EW. Papillomas and atypical papillomas in breast core needle biopsy specimens. Am J Clin Pathol 2004;122:217-21.

22. Sohn V, Keylock J, Arthurs Z, Wilson A, Herbert G, Perry J, et al. 
Breast papillomas in the era of percutaneous needle biopsy. Ann Surg Oncol 2007;14:2979-84.

23. Jacobs TW, Connolly JL, Schnitt SJ. Nonmalignant lesions in breast core needle biopsies to excise or not to excise. Am J Surg Pathol 2002;26:1095-110.

24. Rizzo M, Linebarger J, Lowe MC, Pan L, Gabram SG, Vasquez L, et al. Management of papillary breast lesions diagnosed on core-needle biopsy: clinical pathologic and radiologic analysis of 276 cases with surgical follow-up. J Am Coll Surg 2012;214:280-7.

25. Fu CY, Chen TW, Hong ZJ, Chan DC, Young CY, Chen CJ, et al. Papillary breast lesions diagnosed by core biopsy require complete excision. Eur J Surg Oncol 2012;38:1029-35.

26. Glenn ME, Throckmorton AD, Thomison JB, Bienkowski RS. Papillomas of the breast $15 \mathrm{~mm}$ or smaller: 4-year experience in a com- munity-based dedicated breast imaging clinic. Ann Surg Oncol 2015;22:1133-9.

27. Youk JH, Kim EK, Kwak JY, Son EJ, Park BW, Kim SI. Benign papilloma without atypia diagnosed at US guided 14 gauge core needle biopsy clinical and US features predictive of upgrade to malignancy. Radiology 2011;258:81-8.

28. Hong YR, Song BJ, Jung SS, Kang BJ, Kim SH, Chae BJ. Predictive factors for upgrading patients with benign breast papillary lesions using a core needle biopsy. J Breast Cancer 2016;19:410-6.

29. Ahn SK, Han W, Moon HG, Kim MK, Noh DY, Jung BW, et al. Management of benign papilloma without atypia diagnosed at ultrasound-guided core needle biopsy: scoring system for predicting malignancy. Eur J Surg Oncol 2018;44:53-8. 